OPEN ACCESS

Edited by: Jie He,

University of Connecticut,

United States

Reviewed by:

Gonghu Li,

University of New Hampshire,

United States

Haoquan Zheng,

Shaanxi Normal University, China

Heriberto Pfeiffer,

Universidad Nacional Autónoma de

México, Mexico

*Correspondence:

Ben Liu

ben.liu@ninu.edu.cn

Specialty section: This article was submitted to Nanoscience,

a section of the journal

Frontiers in Chemistry

Received: 31 July 2018 Accepted: 23 October 2018 Published: 09 November 2018

Citation:

Xu D, Lv H and Liu B (2018) Encapsulation of Metal Nanoparticle Catalysts Within Mesoporous Zeolites and Their Enhanced Catalytic

Performances: A Review.

Front. Chem. 6:550

doi: 10.3389/fchem.2018.00550

\section{Encapsulation of Metal Nanoparticle Catalysts Within Mesoporous Zeolites and Their Enhanced Catalytic Performances: A Review}

\author{
Dongdong Xu, Hao Lv and Ben Liu*
}

Jiangsu Key Laboratory of New Power Batteries, Jiangsu Collaborative Innovation Center of Biomedical Functional Materials, School of Chemistry and Materials Science, Nanjing Normal University, Nanjing, China

Metal nanoparticles (NPs) exhibit desired activities in various catalytic reactions. However, the aggregation and sintering of metal NPs usually cause the loss of catalytic performance in practical reaction processes. Encapsulation of catalytically active metal NPs on/within a high-surface-area inorganic support partially resolve such concerns. Microporous zeolites, owing to their rigid frameworks and porous structural features, have been considered as one of ideal inorganic supports. Metal NPs can be easily encapsulated and stabilized within zeolitic frameworks to prevent unwished aggregation during the catalysis. Unfortunately, sole microporous nanochannels (generally $<1 \mathrm{~nm}$ ) in conventional zeolites are not easy to be accessed. The introduction of another set of nanochannel (e.g., mesopore), known as mesoporous zeolites, can greatly improve the mass-transfer efficiency, which is structurally beneficial for most catalytic reactions. The coexistence of micropores and mesopores in inorganic supports provides the synergetic advantages of both fine confinement effect for metal NPs and easy diffusion for organic reactants/intermediates/products. This review focuses on the recent advances in the design and synthesis of mesoporous zeolites-encapsulated metal NP catalysts as well as their desired catalytic performances (activity and stability) in organic reactions. We first discuss the advantages of mesoporous zeolites as the supports and present general strategies for the construction of mesoporous zeolites. Then, the preparation methods on how to encapsulate NP catalysts within both microporous and mesoporous zeolites are clearly demonstrated. Third, some recent important cases on catalytic applications are presented to verify structural advantages of mesoporous zeolite supports. Within the conclusion, the perspectives on future developments in metal NP catalysts encapsulated within mesoporous zeolites are lastly discussed.

Keywords: metal nanoparticle, zeolite, mesoporous, nanoconfinement, mass transfer

\section{INTRODUCTION}

Nanocatalysis by metal nanoparticles (NPs) have always attracted sufficient attention from both scientific researches and industrial applications (Astruc et al., 2005; Narayanan and El-Sayed, 2005; Astruc, 2008; Campelo et al., 2009; Cuenya, 2010). Owing to the high surface-to-volume ratio and surface energy, the surface atoms on metal NPs are supposed to be catalytically active for 
heterogeneous catalytic processes, such as hydrogenation, C-C coupling reaction, carbonylation, oxidation, methanol reforming, fuel cell and so on (Hartwig, 1998; Dyker, 1999; Dupont et al., 2002; Moreno-Manas and Pleixats, 2003; Na et al., 2004; Gilroy et al., 2016). However, precisely because of the high active surface atoms (unstable thermodynamic state), the aggregation and deactivation of the metal NPs by secondary nucleation and recrystallization (or Ostwald ripening) suffer the most serious drawbacks when employed in practical catalytic reactions and hence set great limits on their widely industrial applications (Schmid et al., 1996; Doyle et al., 2003; Challa et al., 2011; Schauermann et al., 2012; Hansen et al., 2013). As a result, the stabilization of metal NPs becomes a challenging research area and can be mainly realized via the combination with soft organic species and hard (or solid) supports (Astruc et al., 2005; Cao et al., 2010). The soft species, also known as capping reagents, are usually classified as polymers (including dendrimers; Corbierre et al., 2001; Crooks et al., 2001), organic or inorganic ligands (Pan et al., 2001), surfactants or micelles (Liz-Marzán and Lado-Touriño, 1996; Kitchens et al., 2003), microemulsions (Capek, 2004), ionic liquids (Dupont et al., 2002; Dupont and Scholten, 2010) and so on. By means of direct chemical binding (generally through heteroatoms) weakly to the surface of metal NPs, these soft protectors will availably block the NP aggregation but also result in the loss of active sites in the meantime due to the subsistent coverage or interfacial interaction (Jin et al., 2017). Additionally, how to resolve the essential question about the recycling potential of these capping metal NPs is always a big challenge. Another significant strategy focuses on the encapsulation of small metal NPs on some hard or solid supports, which will not only prevent NP migration and coalescence but also greatly increase the recycling accessibility (Astruc et al., 2005; Gallon et al., 2007; Campelo et al., 2009; White et al., 2009). Furthermore, the electronic properties of metal NPs on their host support environments can be greatly modified and hence will give rise to various special physical and chemical functions owing to the strong interactions between metal NPs and supports (Ju-Nam and Lead, 2008; Liu et al., 2015, 2017b). Numerous types of nanomaterials can play the role of solid supports, mainly including metal or non-metallic oxides (e.g., $\mathrm{TiO}_{2}, \mathrm{ZrO}_{2}, \mathrm{CeO}_{2}, \mathrm{ZnO}, \mathrm{Al}_{2} \mathrm{O}_{3}, \mathrm{Fe}_{3} \mathrm{O}_{4}, \mathrm{SiO}_{2}$ ); (Astruc et al., 2005; Campelo et al., 2009), carbon (e.g., carbon sphere, nanotube, graphene, porous carbon); (Joo et al., 2001; Sun and Li, 2004), functionalized polymers (Kralik and Biffis, 2001), and porous framework (MOFs, COFs, zeolites, silica); (Dhakshinamoorthy and Garcia, 2012; Farrusseng and Tuel, 2016; Zhu and $\mathrm{Xu}, 2016$ ). The oxide supports can classified as inert (e.g., $\mathrm{SiO}_{2}$ ) and reactive types based on their chemical reactivity. For example, $\mathrm{CeO}_{2}$ is a representative kind of reactive oxide support as an enhanced anchoring effect of Ce-O-M born of strong metal-support interaction can efficiently suppress the phase transformation and improve the thermal stability of metal NPs under higher temperature (Alessandro, 2002). When superparamagnetic $\mathrm{Fe}_{3} \mathrm{O}_{4}$ is utilized as the support, the metal $\mathrm{NP} / \mathrm{Fe}_{3} \mathrm{O}_{4}$ nanomaterials can be easily recovered using a permanent magnet and therefore reused in many runs (Jacinto et al., 2008). Carbon nanostructures, owing to their intrinsic properties, such as high surface area, high electrical conductivity, and unique physical properties and so on, are extremely attractive supports and have been widely employed in the heterogeneous catalysis process (Wildgoose et al., 2006; Kamat, 2009; Liu et al., 2016, 2018). Furthermore, the carbonaceous surface can be easily modified to stabilize the metal NPs. In recent years, the combination between porous frameworks and metal NP technologies has attracted sufficient research and obtained fruitful results (Joo et al., 2001; He et al., 2003; Yang et al., 2003; Mandal et al., 2004; Rioux et al., 2005; White et al., 2009; Aijaz et al., 2012; Lu et al., 2012; Xu et al., 2012). A porous framework generally composed of interconnected network system of pores with distinct diameters, which exist in many natural substances and can be easily created in most of solid chemical nanomaterials. The pores inside the solid structures (usually called interior pore system, while exterior surface can only be accessed in non-porous structures) can nanoconfine the size and shape of metal NPs and inhibit their aggregation and further growth. The throughout pore network renders the masstransfer more achievable during the catalysis (Satterfield, 1970; Liu et al., 2010, 2017a). Furthermore, the different components of frameworks, dimensions of porous nanochannels, pore sizes and corresponding combinations (hierarchical porosities) endow porous supports with more functional features (Davis, 2002a; Rowsell and Yaghi, 2004). Mesoporous silica with numerous pore sizes, morphologies, and mesochannels have been successfully synthesized by different strategies and also utilized as the support media of metal NPs (Kresge et al., 1992; Zhao et al., 1998; Ciesla and Schüth, 1999; Wan and Zhao, 2007). Additionally, porous carbon materials and MOFs have also been widely prepared to act as the supports for some particular catalytic applications. Each porous support possesses its intrinsic advantages (e.g., carbon receiving greater thermally stabilization) and disadvantages (for example, complex synthesis processes for mesoporous carbon, low framework stabilization of conventional mesoporous silica and MOFs); (Zhao et al., 2006; Arico et al., 2011; Slater and Cooper, 2015).

Compared to abovementioned support media, porous zeolites, due to their inherent structural features, are promised to be an important family of solid supports for the encapsulation of metal NPs. Zeolites, as a kind of highly crystalline inorganic materials having orderly distributed micropores with the diameter $<1 \mathrm{~nm}$, have many applications, especially in the field of petrochemical industry (Corma, 1997; Cundy and Cox, 2005; Li and Yu, 2014; Primo and Garcia, 2014; Zaarour et al., 2014). The zeolite framework commonly consists of $\mathrm{TO}_{4}$ tetrahedra ( $\mathrm{T}$ denotes $\mathrm{Si}, \mathrm{Al}$, and $\mathrm{P}$, etc.) which will build lots of senior structures. Up to 2018, there are totally 239 zeolite framework types (http://www.iza-structure.org/databases/) collected by the International Zeolite Association (IZA) (Guo et al., 2017). Based on different pore windows from $\mathrm{TO}_{4}$, conventional zeolites can be categorized into small, medium, large, and extra-large pores. The catalytic activities of zeolites largely depend on the structural and compositional features, including pore sizes, channel types and framework compositions. Compared to other catalyst supports, zeolites possess an important and unique feature, known as shape selectivity (e.g., reactants, products and 
transition-states). When utilized as the solid supports, the regular cavities and nanochannels in zeolites can act as the spaces and sites for the encapsulation of extraneous NPs. When metal NPs form and grow inside the micropores, they would be wellconfined at the level of ultrasmall sizes and be not easy to escape from these interconnected cavities. For example, widely studied and applied zeolite ZSM-5 (MFI topology) possesses 10 -numbered rings and admits the largest pore accessibility of ca. $0.64 \mathrm{~nm}$ (Kokotailo et al., 1978), which will greatly confine the crystalline growth of embedded metal NPs. Rigid framework of zeolites offers the important advantages for their applications in harsh catalytic environments; their unique nanochannels also provide the opportunity for shape-selective catalysis (Corma, 1997; Weitkamp, 2000; Davis, 2002a; Moller et al., 2012). So far, many reports on the preparation of zeoliteencapsulated metal NPs show the enhanced catalytic activities. For example, Wang et al. (2016) reported the preparation of ultrasmall Pd NPs encapsulated in situ within nanosized silicalite1 by one-step hydrothermal synthesis. The resultant catalyst showed a highly efficient $\mathrm{H}_{2}$ generation activity toward the decomposition of formic acid. Liu et al. (2017a) prepared single Pt atoms and Pt NPs with exceptionally high thermal stability within purely siliceous MCM-22 and the catalyst presented good catalytic activity in the dehydrogenation of propane to propylene. Zhang et al. (2017) found that Pd@Beta catalyst exhibited superior selectivity for the hydrogenation of the nitro group when fixing $\mathrm{Pd} \mathrm{NPs}$ inside Beta zeolite crystals. In addition, there are still many such cases in which metal NPs were well-immobilized inside specific zeolites that exhibited enhanced catalytic performances (Laursen et al., 2010; Moreno et al., 2013; Mielby et al., 2014; Xing et al., 2014; Cheng et al., 2015; Ren et al., 2015; Rubio-Marques et al., 2015; Hosseiniamoli et al., 2018; Tang et al., 2018; Yang et al., 2018).

It is easy to envision that the mass-transfer processes will be greatly restricted as the micropores have been occupied by metal NPs especially involving organic molecules with larger dimensions (Kärger and Ruthven, 1992; Chen et al., 1994; Tao et al., 2006). For purpose of overcoming this shortcoming, massive efforts have been made to construct zeolitic frameworks with larger aperture ( $\mathrm{Li}$ and $\mathrm{Yu}, 2014$ ) or create a new set of pore system (known as mesopores) inside the conventional bulk zeolites (Egeblad et al., 2008; Perez-Ramirez et al., 2008; Lopez-Orozco et al., 2011; Möller and Bein, 2013; Parlett et al., 2013; Perego and Millini, 2013; Serrano et al., 2013). Comparatively speaking, the latter is simpler to implement. As shown in Figure 1A, purely microporous zeolites (e.g., ZSM-5), ordered mesoporous materials (e.g., MCM-41), and mesoporous zeolites (e.g., meso-ZSM-5) show obviously different BrunauerEmmett-Teller curves and pore size distributions based $\mathrm{N}_{2}$ isotherms (Perez-Ramirez et al., 2008). It clearly illustrate that mesoporous zeolites possess both the micropores and mesopores (hierarchical pore systems) inside one crystal, which would be greatly helpful for the mass thransfer of organic molecules. In mesoporous zeolites-encapsulated metal NPs catalysts, metal surfaces (providing the catalytic active sites), the micropores or mesopores (immobilizing and stabilizing the metal NPs) and interconnected mesopores (accelerating the transfer of reactants and products) together built an excellent catalysis system. As schemed in Figure 1B, the metal NPs can be immobilized inside both micropores and mesopores. The reactants go through the catalysts along the interconnected mesopores and accelerate the organic reactions. The interior metal NPs also participate in the catalysis, which is not accessible in sole microporous systems.

Considering all of above aspects, this review will highlight the recent progresses on the construction of mesoporous zeolitesencapsulated metal NPs and the investigation of their enhanced activities on various catalytic applications. Conventional zeolitesencapsulated counterparts are not discussed in detail here as some excellent review papers have presented before (Farrusseng and Tuel, 2016; Wang et al., 2018b). In current review, we firstly concern design principles and construction of mesoporous zeolites. Second, we place special focus on how to immobilize or introduce metal NPs into the mesoporous zeolites. Some reported cases will be clearly presented to illustrate the synthetic process of this type of composite catalysts. Third, several typical organic reactions based on mesoporous zeolitesencapsulated metal NPs are recommended to confirm their superior catalytic performances. This review is prospected to provide some important insights on the construction of

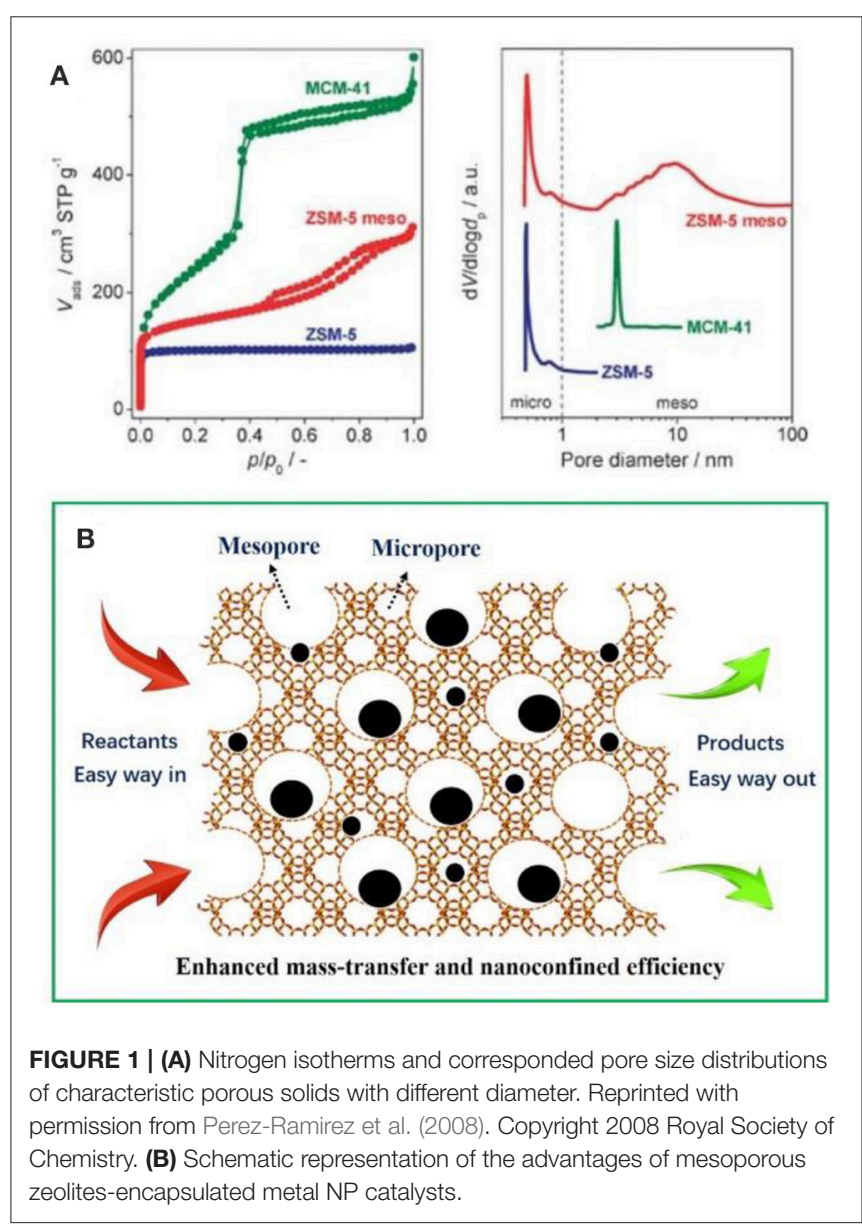


stabilized metal NPs within mesoporous zeolites and how to tune the catalytic performances based on the distinct supports media.

\section{CONSTRUCTION OF MESOPOROUS ZEOLITES}

Considering the advantages of hierarchically mesoporous zeolites in various catalytic reactions, many attempts have been made to build the meospores in conventional zeolites. Furthermore, the preparation of mesoporous zeolites is the precondition for the encapsulation of metal NPs. Therefore, the synthetic strategies for mesoporous zeolites are briefly presented here (Lopez-Orozco et al., 2011; $\mathrm{Na}$ et al., 2013; Parlett et al., 2013; Serrano et al., 2013; Li et al., 2014a; Shi et al., 2015; Schwieger et al., 2016). The main methods can be generally classified as four aspects: (i) hardtemplating, (ii) soft-templating, (iii) post-synthetic treatment, and (iv) stacking or assembly of zeolite crystals. As shown in Figure 2, the strategies and the detailed routes are clearly presented schematically.

Most of removable and inert solids with the nanoscale sizes can be employed to act the hard templates for the synthesis of mesoporous zeolites by a hard-templating method, for example, carbon nanostructures (NPs, nanowires, nanotubes, aerogel, ordered porous frameworks), $\mathrm{CaCO}_{3} \mathrm{NPs}$, polystyrene arrays, biological wood and starch (Schwieger et al., 2016). After the removal of these solid species by calcination or acid dissolution, abundant mesopores can be released while the order degree of these mesopores mainly depends on the nanostructures of hard templates. As an instance, three-dimensional ordered mesoporous carbon with large mesopores was developed to construct ordered porous zeolites with distinct framework topologies (e.g., MFI, LTA, FAU, BEA); (Chen et al., 2011). Nevertheless, although the synthesis of mesoporous zeolites using hard-templating methods is greatly high-efficiency, this strategy is often restricted due to the multistep procedures, high costs and health hazards involving during the synthesis.

Soft-templating strategy, referring to the molecular selfassembly of amphiphilic surfactants, is considered as the most possible way to build ordered mesoporous zeolites. The ordered mesopores are greatly favorable for the mass-transfer in the catalytic processes. Choi et al. (2009) and Na et al. (2011) have successfully designed a series of amphiphilic molecules containing quaternary ammoniums, also known as bifunctional surfactants, which were further employed to direct the growth of zeolitic frameworks and ordered mesoscale structures by one-step hydrothermal synthesis. As a consequence, lamellar MFI zeolite nanosheets with a single-unit-cell thickness along $b$-crystallographic axis and a hexagonally-ordered mesoporous aluminosilicate, consisted of truly crystalline zeolitic walls, have successfully obtained. By means of the introduction of aromatic groups into the hydrophobic chain, Xu et al. $(2014 \mathrm{a}, \mathrm{b})$ prepared single crystalline mesostructured zeolite nanosheets and the ones with $90^{\circ}$ rotational boundaries due to the $\pi-\pi$ stacking between benzene rings. Additionally, Liu et al. (2012) and Zhu et al. (2014) developed the hydrophilic cationic polymer (e.g., polydiallyldimethylammonium chloride, polystyrene-co4-polyvinylpyridine) to produce single-crystalline mesoporous zeolite Beta and MFI, respectively. The soft-templating method provides the possibility for the better control of both zeolitic framework topologies and mesoporous structures. However, the current synthesis is limited to zeolite MFI or Beta, and therefore how to design the effective organic surfactants for synthesizing other kinds of zeolitic topologies or mesoporous nanostructures is still a big challenge.

The selective removal or extraction of zeolite framework atoms (e.g., $\mathrm{Si}, \mathrm{Al}$, or $\mathrm{Ti}$ ) via post-treatment by acid, alkali, steaming, or other similar methods, can produce some mesopores inside the bulk zeolites. Through the precise control of the desilication or dealumnization from the zeolite frameworks, one could obtain mesoporous zeolites with different $\mathrm{Si} / \mathrm{Al}$ ratios and desired catalytic sites. This method can effectively result in abundant intracrystalline mesopores but simultaneously decrease the crystallinity of zeolites partially (Groen et al., 2005). The intercrystalline mesopores are a type of mesopores from the stacking of nanocrystals and can be easily found in most of nanomaterials. Through the synthesis of nanosized zeolite crystals, abundant mesopores although in disordered forms but may be destroyed again after the dispersion in the solvents. After the treatment like swelling, intercalation, delamination and pillaring, some layered zeolites can be turned into ultrathin zeolite layers, which further assemble into mesoporous nanostructures. A typical case is the delamination of as-synthesized MCM-22 into two-dimensional ITQ-2, which possess high surface areas and improved catalytic performances (Corma et al., 1998).

Another strategy to construct mesopores in zeolites focuses on the particular crystalline growth model of some particular zeolites. For example, through the intergrowth of MEL/MFI, selfpillared pentasil zeolite with house-of-cards-like morphology was successfully prepared. The hierarchical porosity was created inside the three-dimensional nanosheet assembly by the repetitive branching of the MFI-type zeolitic nanosheets (Zhang et al., 2012). The synthesis process based on this strategy is relatively simple (no need of special templates or tough condition) but only happens in a handful of zeolitic topologies.

Based on the discussion of the strategies to construct mesopores inside zeolites, the different synthetic routes obviously possess their intrinsic advantages and disadvantages. One should consider these processes comprehensively before the choice of a certain route and further combine the corresponded application fields. For instance, when utilized as a porous support, all of routes are suitable for the post-synthetic encapsulation of metal NPs (discussed in next part) but not for the one-step formation of mesoporous zeolite-encapsulated metal NPs composites.

\section{ENCAPSULATION STRATEGIES FOR METAL NPS}

The encapsulation of metal NPs inside the porous zeolites can be mainly classified into two types of strategies: post-synthetic process and one-step in situ confinement. The post-synthetic 


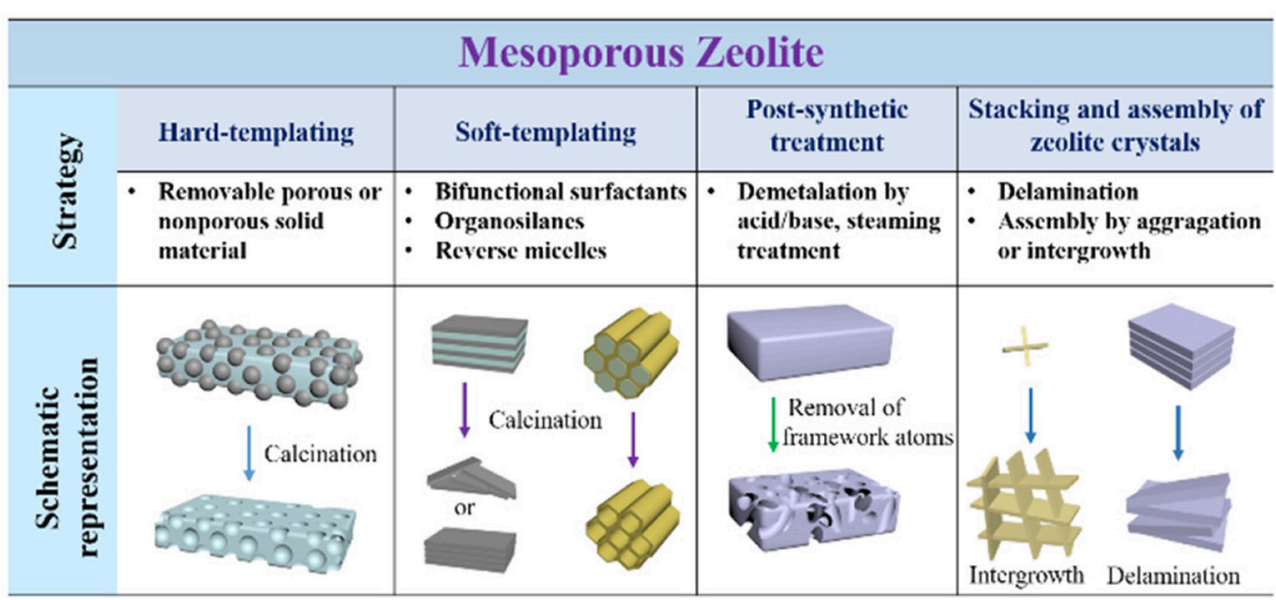

FIGURE 2 | Schematic representation of the different strategies for the construction of mesoporous zeolites.

strategy refers to the introduction of metal NPs after the complete construction of zeolitic framework. Contrastively, the one-step confinement method needs the co-crystallization of zeolites and metallic precursors, and follows an in-situ reduction to obtain metal NPs.

\section{Post-synthetic Encapsulation Strategy}

The post-synthetic strategy is widely utilized to introduce metal NPs into zeolite crystals as it does not limit the framework sorts of zeolites. The process based on this strategy can be reached by means of the soak of zeolite supports in metal colloids (or NPs) or soluble metal precursors. The channels and pores inside zeolites provide the region for the loading of metal NPs. The diffusion of metal NPs or precursors is usually accelerated in a set of relatively large micropores, especially in mesopores. Actually, the diffusion of metal NPs is quite difficult to enter into the interior structures of zeolites where most of them only load at the surface (Wang et al., 2018a). As a representative example, by means of a particular structural transformation of two-dimensional (2D) zeolite into threedimensional (3D), Liu et al. (2017c) had successfully imbedded single Pt atoms and Pt NPs inside siliceous MCM-22 (Pt@MCM22). As shown in Figure 3, during the swelling process of the lamellar precursor MCM-22 where MWW layers were expanded by the surfactant hexadecyltrimethylammonium, subnanometric $\mathrm{Pt}$ species were incorporated into internal channels between individual MWW layers. After the removal of organic species by calcination, lamellar MCM-22 would turn into 3D MCM-22 and simultaneously Pt species were well-confined in external cups (hemi-cages) or encapsulated in the supercages. Subnanometric Pt species were tightly entrapped inside zeolite MCM-22. Due to structural features, Pt@MCM-22 possessed exceptionally high thermal stability even after the treatment in air up to $540^{\circ} \mathrm{C}$ and showed desired size-selective catalytic activity for the hydrogenation of alkenes.

Most of cases for the preparation of zeolite-encapsulated metal NP catalysts focus on the strategy using soluble metal precursors, also called wetness impregnation method. In this process, metallic species can easily diffuse into the crystal inner and load in the micropores or mesopores after the removal of solvent (e.g., water). Following a conventional reduction step, the metal precursors can be reduced into elementary metal NPs. A synthesis methodology using thiol-based organometallic complexes was presented to encapsulate metal NPs within LTA zeolites, which were successful in encapsulating $1-2 \mathrm{~nm}$ monometallic (e.g., Pt, Pd, Ir, Rh, and Ag) or alloyed NPs (e.g., AuPd, AuPt, and PdPt); (Choi et al., 2010; Otto et al., 2016). In pure microporous zeolites, limited by the small diameter of micropores, the size of resultant metals was usually confined in the region of below $2 \mathrm{~nm}$. As for mesoporous zeolite supports, it is more easy to immobilize metal NPs owing to the presence of the larger mesopores. So far, many kinds of metal NPs (Pt, Pd, $\mathrm{Ru}, \mathrm{Ag}$, and the corresponded alloys) has been immobilized in mesoporous zeolites with different framework topologies based on this wetness impregnation method (Wang et al., 2015, 2018a; Mendes et al., 2017; Chen et al., 2018; Zhang et al., 2018). Due to the intrinsically structural advantages of mesoporous zeolites and confinement effects for the immobilized metal NPs, all of these reported composite catalysts had exhibited superior catalytic activity in various catalytic reactions (Liu and Corma, 2018).

\section{In situ Confinement Strategy}

Metal NPs or precursors can also be introduced into the zeolite crystal inners via the one-pot hydrothermal synthetic process. In this method, as-synthesized metal NPs or soluble metallic precursors were firstly mixed with the synthetic gel for zeolites (e.g., structural-directing agents, silica resources, water, sodium hydroxide, etc.), and then turned into high temperature for the crystallization of zeolites. The as-synthesized composite products were further calcined to remove the organic species and reduced under reduction agents (e.g., $\mathrm{H}_{2}, \mathrm{NaBH}_{4}$ ) to form metal NPs. Laursen et al. reported the synthesis of zeolite-encapsulated Au NPs for size-selective satalysis (Laursen et al., 2010; Højholt et al., 2011). Ultrasmall Au NPs were uniformly immobilized in silica 


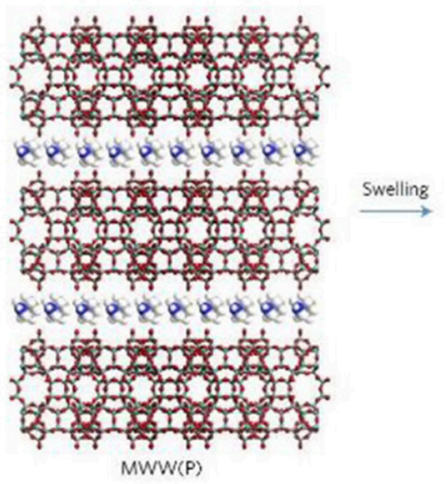

Hexamethylenimine
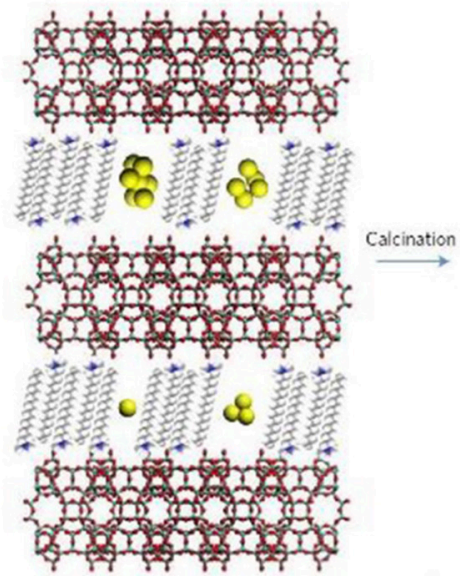

QWCOCLC стмA

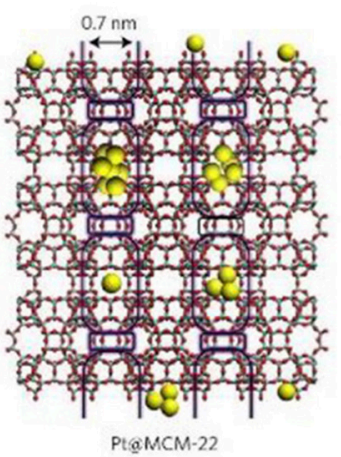

Pt cluster

FIGURE 3 | Schematics of the processes for the preparation of Pt@MCM-22. Reprinted with permission from Liu et al. (2017c). Copyright 2016 Macmillan Publishers Ltd: (Nature Materials).

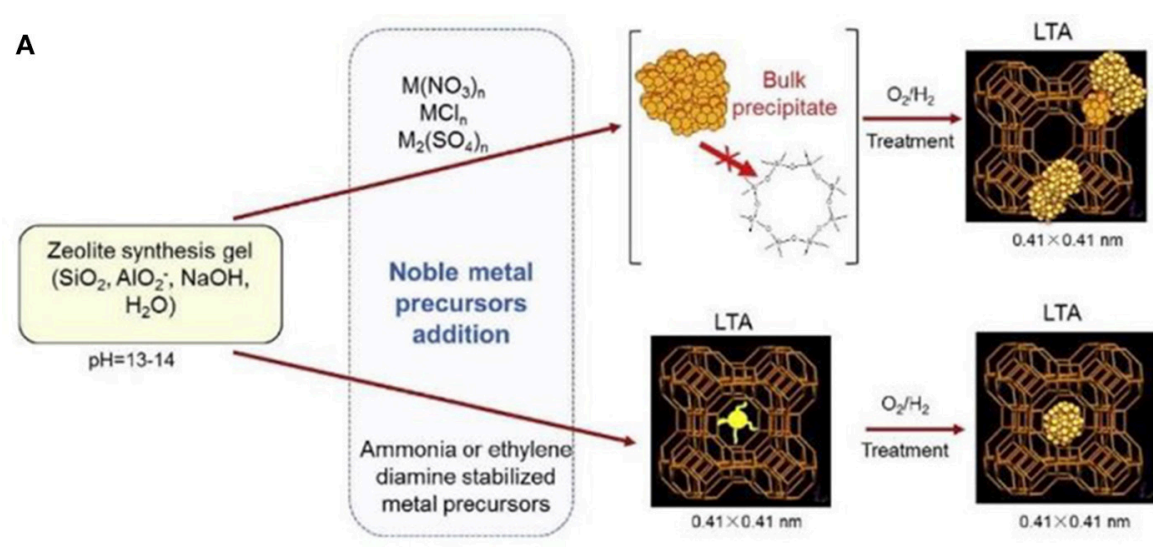

B
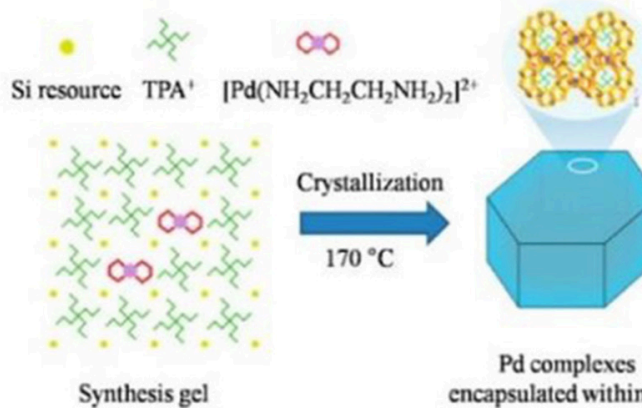

Pd clusters

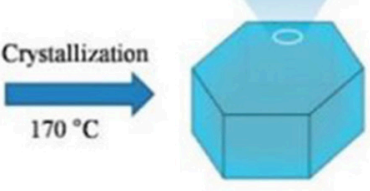

Pd complexes encapsulated within S-1

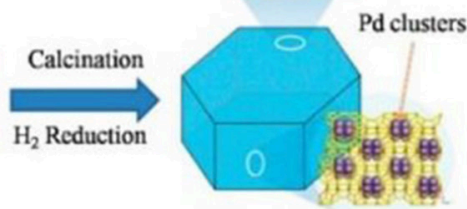

Pd clusters cncapsulated within S-1

FIGURE 4 | Schematic representation for the formation of zeolite-encapsulated metal NPs via one-pot hydrothermal synthesis process. (A) The synthesis process by using metal cations as the precursors (top) and the ligand-stabilized metal precursors (below) to produce LTA-encapsulated metal NPs. Reprinted with permission from Wu et al. (2014). Copyright 2014 Elsevier. (B) The MFI-encapsulated Pd NPs synthesized by using $\left[\mathrm{Pd}_{(}\left(\mathrm{NH}_{2} \mathrm{CH}_{2} \mathrm{CH}_{2} \mathrm{NH}_{2}\right)_{2}\right]^{2+}$ as the Pd precursor. Reprinted with permission from Wang et al. (2016). Copyright 2016 American Chemical Society.

matrix that would be turned into a zeolite phase (silicalite-1). Au NPs embedded inside slicalite-1 mostly possessed a diameter of 1-2 nm; no obvious change in the original size can be seen even under calcination under $500^{\circ} \mathrm{C}$. The crystalline zeolite frameworks played the role to confine the growth of Au NPs. However, in this process, a phase separation phenomenon often 


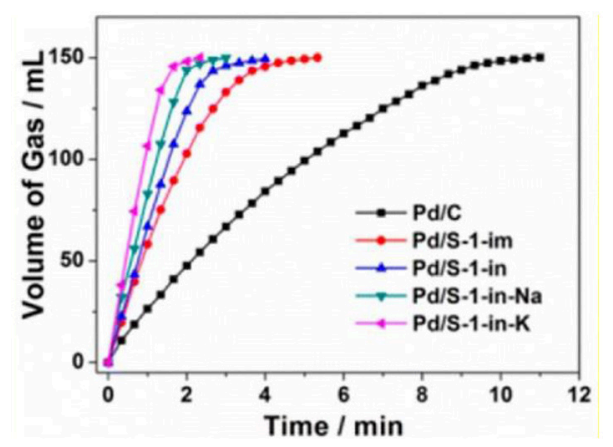

FIGURE 5 | Volume of the generated gas $\left(\mathrm{CO}_{2}\right.$ and $\left.\mathrm{H}_{2}\right)$ vs. time for the dehydrogenation of FA-SF over $\mathrm{Pd} / \mathrm{C}$ and $\mathrm{Pd} / \mathrm{S}-1$. Reprinted with permission from Wang et al. (2016). Copyright 2016 American Chemical Society.

happened due to the harsh crystalline conditions for zeolites, resulting in the formation of larger metal aggregates. Therefore, the usage of metal NPs as the precursors is not widely applied for the construction of zeolite-encapsulated metal catalysts.

Comparatively speaking, metallic precursors are easy to be encapsulated inside the resultant zeolites. Wu et al. (2014) reported the encapsulation of noble metal NPs (Pt, Pd, Rh, Ir, Re, and $\mathrm{Ag}$ ) in LTA voids (Figure 4A). If only metal cations were employed, premature precipitation of these metal hydroxides would be mainly formed. When some ligands (e.g., $\mathrm{NH}_{3}$, ethylenediamine) were used to stabilize metal cations and protect cationic moieties against precipitation, avoiding premature precipitation resulted in the zeolitic framework units to grow around the ligand-stabilized metal precursors. Finally, a series of metal NPs were successfully encapsulated within the small micropores of LTA zeolite. These composite materials exhibited excellent shape selectivity in both catalytic oxidative dehydrogenation of alkanols and hydrogenation of alkenes. Another important case by using this strategy was reported by Wang et al. (2016). The authors utilized organometallic complex $\left(\left[\mathrm{Pd}\left(\mathrm{NH}_{2} \mathrm{CH}_{2} \mathrm{CH}_{2} \mathrm{NH}_{2}\right)_{2}\right]^{2+}\right)$ as the $\mathrm{Pd}$ precursor to produce well-dispersed and ultrasmall $\mathrm{Pd}$ NPs in nanosized silicalite-1 (MFI). Pd NPs were successfully encapsulated within the intersectional channels of MFI with a diameter of $\sim 1.8 \mathrm{~nm}$ (Figure 4B), which could be further tuned via the different synthetic conditions (using $\mathrm{NaOH}$ or $\mathrm{KOH}$ as the base source). They had also reported the preparation of subnanometric bimetallic NPs of $\mathrm{Pd}-\mathrm{M}(\mathrm{OH})_{2}$ $(\mathrm{M}=\mathrm{Ni}, \mathrm{Co})$ using the similar synthetic methods (Sun et al., 2017). These MFI-encapsulated metal NPs presented superior catalytic performance toward the dehydrogenation of formic acid.

From abovementioned cases, how to balance the crystallization growth of both zeolites and metal NPs is quite important for obtaining the well-dispersed and size-uniform metal NPs inside zeolite crystals. The type of metallic precursors and other synthetic conditions (e.g., alkalinity, silica sources) should be carefully considered. The corresponded catalytic activity may generally depend on how strong the confinement effect is between zeolite frameworks and metal NPs.

\section{CATALYTIC APPLICATIONS}

When metal NPs are encapsulated inside conventional zeolites, they are mainly confined in micropores and randomly distributed throughout the zeolite crystals. This type of catalysts proves to be appropriate for organic catalysis involving only small molecules. For example, when Pd cluster-containing zeolite catalysts ( $\mathrm{Pd} / \mathrm{S}-1$, as shown in Figure 4B) was utilized to catalyse the dehydrogenation of formic acid and sodium formate (FA-SF) to produce $\mathrm{H}_{2}$ (Figure 5), $\mathrm{Pd} / \mathrm{S}-1$ exhibited complete decomposition of FA in a short time compared to the commercial $\mathrm{Pd} / \mathrm{C}$ catalyst, also better than the $\mathrm{Pd} / \mathrm{S}-1$ catalyst obtained by the impregnation-prepared catalysts (Wang et al., 2016). However, although exhibiting excellent catalytic activity in the dehydrogenation process, this catalyst may miss their ability in organic reactions for the larger molecules, due to the limitation of small microporous channels or accessible void spaces. Additionally, even if the catalytic reactions involving organic molecules with small diameters (less than the micropores) happens in this type of composite catalysts, relatively slow diffusion in the interior zeolites would greatly influence the catalytic processes.

On the other hand, pure zeolite-encapsulated metal NP catalysts will be powerless to catalyse the reactions with big molecular volume (Ju et al., 2015; Dai et al., 2016; Kosinov et al., 2018). The difficulty for mass transfer and bulky molecule catalysis can be significantly improved via producing mesopores inside conventional zeolites as abovementioned. When immobilized on mesoporous zeolites, metal NPs can be not only distributed inside micropores, but also dispersed on the external surface of the mesopores. Those provide more catalytically active sites and easier ways to across the catalysts.

Han et al. (2018) and Kim et al. (2014) successfully prepared mesoporous zeolite nanosponge-encapsulated Co NPs as the efficient catalysts for Fischer-Tropsch (FT) synthesis. In the presence of amphiphilic surfactants containing multiquaternary ammoniums, zeolite nanosponge with ultrathin walls, which could be irregularly interconnected into three-dimensional mesoporous networks, had been synthesized. By means of the incipient wetness impregnation process using $\left[\mathrm{Co}\left(\mathrm{NO}_{3}\right)_{2} \cdot 6 \mathrm{H}_{2} \mathrm{O}\right]$ as the metallic precursor, Co NPs were immobilized into the mesopores. Due to the narrow distribution of mesopore diameters, Co NPs possessed the uniform NP diameters of $4 \mathrm{~nm}$ (Figures 6A,B). Compared to bulk MFI zeolite or $\gamma-\mathrm{Al}_{2} \mathrm{O}_{3}$ supports, the cobalt-supporting zeolite nanosponges had higher catalytic performance in FT synthesis (Figure 6C). Owing to the strong confinement effect of mesopores, the catalyst exhibited high resistance to sintering, high conversion of $\mathrm{CO}$, and long catalytic lifetime. Meantime, the thin MFI walls contributed to a high selectivity to branched hydrocarbons in the gasoline range $\left(\mathrm{C}_{5}-\mathrm{C}_{11}\right)$. The authors further increased the loading amount of Co within zeolite Beta or MFI nanosponge, resulting in the construction of Co nanowires or networks along the mesoporous nanochannels (Figures 6D,E); (Han et al., 2018). Although the mesopores were blocked by Co nanostructures, the accessibility through microporous windows on the mesopore walls could also ensure a high catalytic activity toward FT 

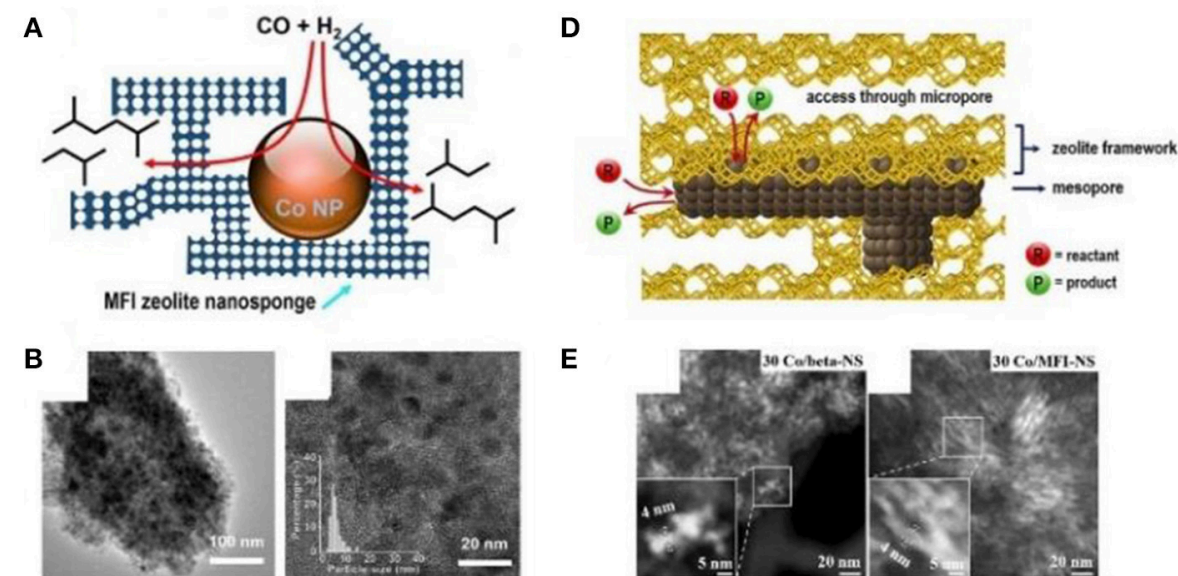

$\mathbf{E}$
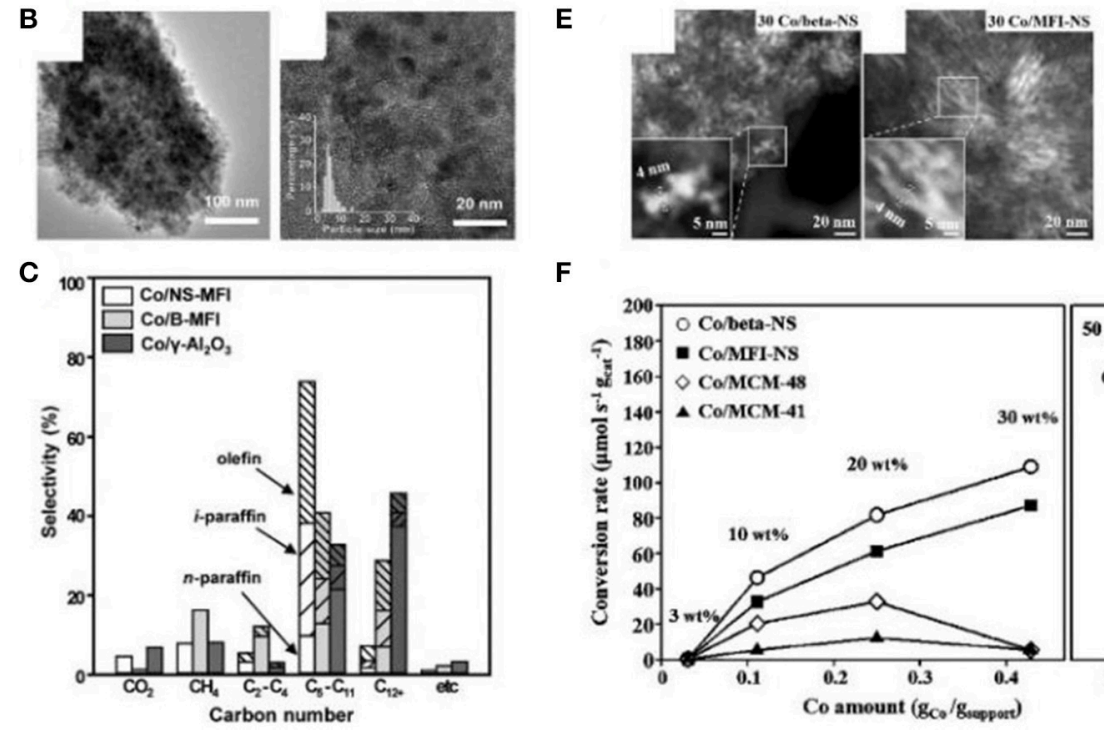

$\mathbf{F}$

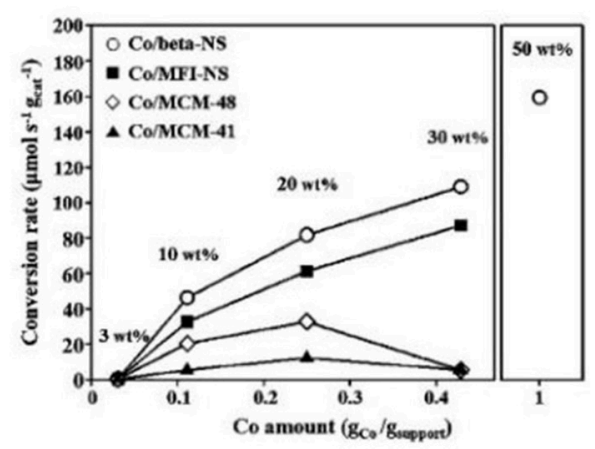

FIGURE 6 | Mesoporous zeolite nanosponge-encapsulated Co NPs for Fischer-Tropsch reaction. (A) Schematic representation, (B) TEM images, and (C) product selectivity of mesoporous MFI nanosheets-encapsulated Co NPs catalysts. Reprinted with permission from Kim et al. (2014). Copyright 2014 American Chemical Society. (D) Schematic representation, (E) TEM images, and (F) CO conversion rates of mesoporous Beta and MFI nanosponge-encapsulated Co NPs with high loading amount, accessible through microporous windows at the encasing mesopore walls. Reprinted with permission from Han et al. (2018). Copyright 2017 American Chemical Society.

synthesis (Figure 6F). Furthermore, the zeolite nanospongeencapsulated Co nanostructures also exhibited high catalytic performance in benzene hydrogenation and furfural-to- $\gamma$ valerolactone conversion.

Based on in situ confinement strategy, mesoporous silicalite-1 nanocrystals-encapsulated Pd NPs (Pd@mnc-S1) could be wellconstructed by Cui et al. (2016) After mixing silica, $\mathrm{Pd}^{2+}$, small amount of polyvinyl pyrrolidone (PVP) and water, silicalite-1 nanocrystals with built-in mesopores were synthesized following the Kirkendall growth process (Figure 7A). The presence of PVP could prevent the aggregation of palladium oxide or hydroxide NPs under the high $\mathrm{pH}$ value. Metallic Pd NPs were obtained via successive calcination of the as-synthesized products in oxygen and hydrogen atmospheres. Pd NPs with a diameter in the range of $2 \sim 5 \mathrm{~nm}$ exhibited a high thermal and chemical stability, indicating the high encapsulation of Pd NPs inside the framework of silicalite-1 nanocrystals. The intrinsic micropores and Pd NPs in Pd@mnc-S1 resulted in good shape selectivity for a series of model reactions, such as hydrogenation, oxidation and C-C coupling reactions (Figure 7B). For example, catalytic hydrogenation conversion of nitrobenzene into aniline could be efficiently completed using Pd@mnc-S1 as the catalyst. However, only a negligible amount of 1-nitronaphthalene would be converted into naphthalen-1-amine over Pd@mnc-S1. As well-known, 1-nitronaphthalene possess the molecule size about $7.3 \times 6.6 \AA$, bigger than the micropores of zeolite MFI $(5.3 \times$ $5.6 \AA)$, resulting in the inability of Pd@mnc-S1 to catalyse the bulk organic molecules. The same results of shape selectivity had been found in the oxidation and $\mathrm{C}-\mathrm{C}$ reactions. Additionally, the presence of mesopores inside zeolite supports greatly enhanced the mass-transfer efficiency and thus gave rise to the high catalytic activity. The authors further found that the number of acid sites in mesoporous H-ZSM-5 frameworks could play as "solid ligands" to activate the embedded Pd NPs for organic synthesis (e.g., Suzuki coupling reactions); (Ke et al., 2017).

In order to catalyse the hydrodeoxygenation of the phenolic compounds in bio-oil to alkanes, Wang et al. (2015) immobilized $\mathrm{Ru}$ NPs into $b$-axis-aligned mesoporous ZSM-5 (Ru/HZSM-5$\mathrm{OM})$ as an efficient catalyst. Owing to the open mesopores and rich exposed acid sites, Ru/HZSM-5-OM exhibited better catalytic activity in the hydrodeoxygenation of bulky 2, 6dimethoxyphenol (as a model reaction) than bulk or mesoporous 

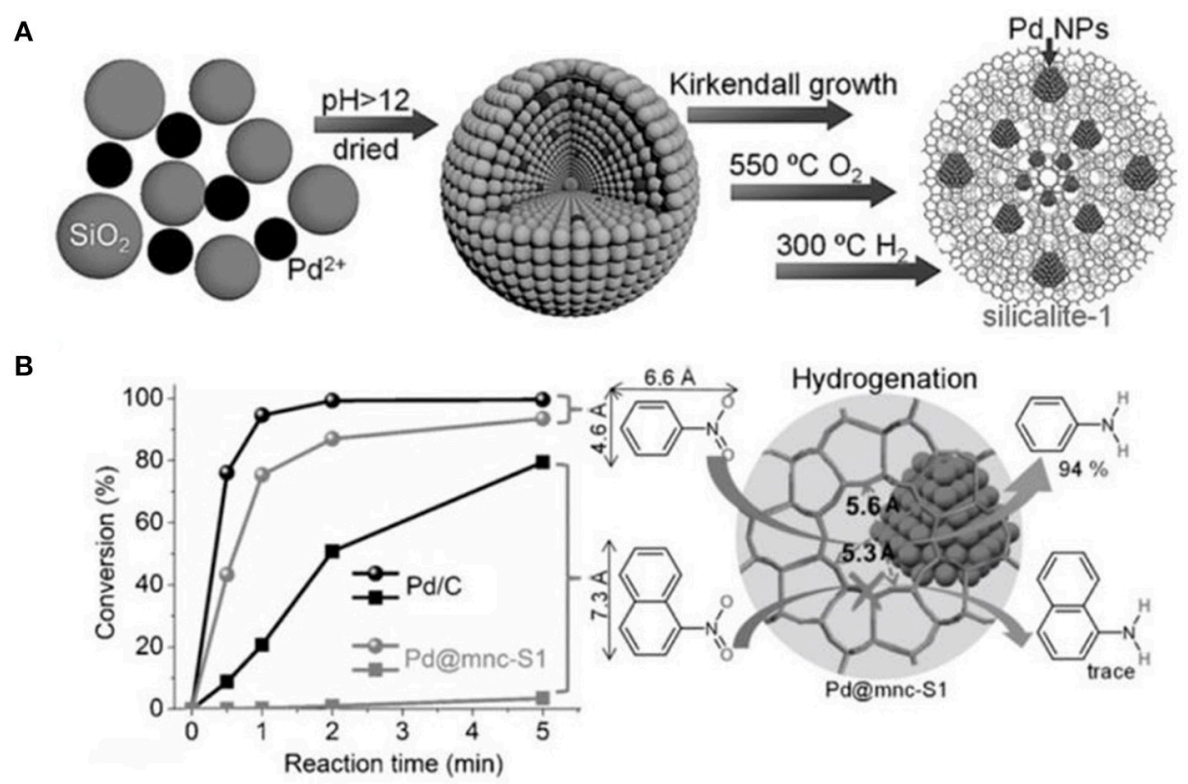

Oxidation reaction:

\section{C-C coupling reaction:}
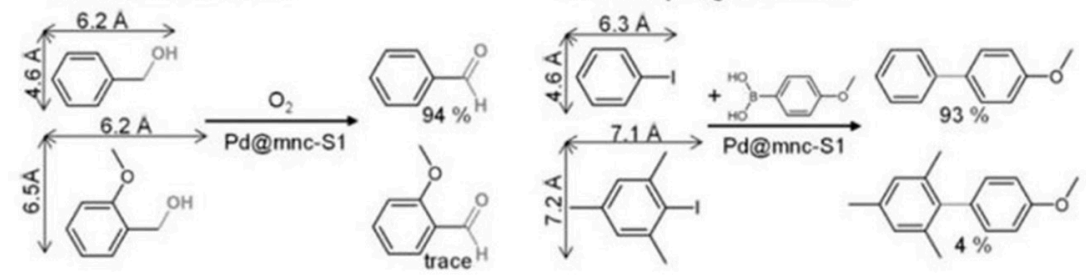

FIGURE 7 | Mesoporous silicalite-1 nanocrystals-encapsulated Pd NPs (Pd@mnc-S1) with enhanced catalytic activity in various organic reactions. (A) The synthesis scheme for the preparation of Pd@mnc-S1 via in situ confinement process. (B) The different organic reactions (hydrogenation, oxidation, and C-C coupling reactions) catalyzed by Pd@mnc-S1. Reprinted with permission from Cui et al. (2016). Copyright 2016 Wiley.

HZSM-5-encapsulated Ru NPs. This is because the bulky reactant molecule could easily transfer through the open mesopores and complete the reaction on the external/mesopore acid sites in HZSM-5-OM. A high conversion rate and cyclohexane selectivity could be reached when using Ru/HZSM-5-OM as the catalyst. $\mathrm{Ru} / \mathrm{HZSM}-5-\mathrm{OM}$ also presented excellent recyclability, keeping the high conversion (95.8\%) and cyclohexane selectivity (69.0\%) after recycling ten times (Figure 8). Due to the fine confinement effect from HZSM-5-OM, Ru NPs could be well-stabilized in zeolitic framework as no $\mathrm{Ru}$ species in the liquid had been detected under the reaction conditions or after the recycling test.

Another interesting strategy to build porous zeoliteencapsulated metal NP catalysts is promised to utilize hollow zeolites as the inorganic supports (Dong et al., 2003; Ren et al., 2007; Li et al., 2014b,c; Pagis et al., 2016; Prieto et al., 2016). The structural features endow them into hierarchically macro-microporous or macro-meso-microporous systems, both of which are structurally beneficial for mass transfer of the reactants and products. The active sites of metal NPs on relatively thin shell are easily accessible. For example, Li et al. (2014b) produced Pt NPs inside hollow silicalite-1 crystals as the composite catalysts for size-selective hydrogenation of aromatic compounds (Figure 9A). The hydrogenation product

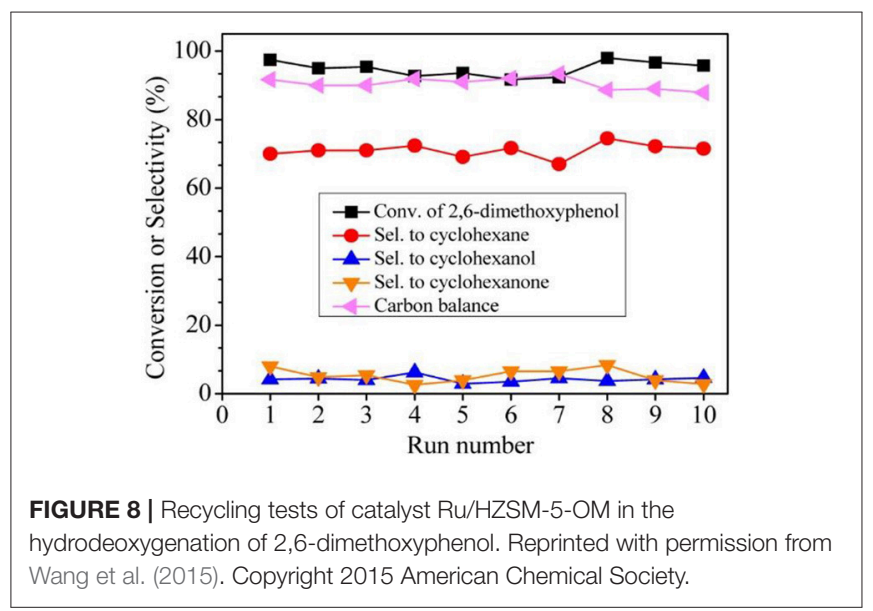

of methylcyclohexane from toluene possessed a kinetic diameter less than MFI micropores and thus easily diffused through the zeolitic shell. Contrastively, the product of trimethylcyclohexane from mesitylene could not go across the zeolite shell to reach the reaction sites on Pd NPs, resulting in the poor catalytic activity of 


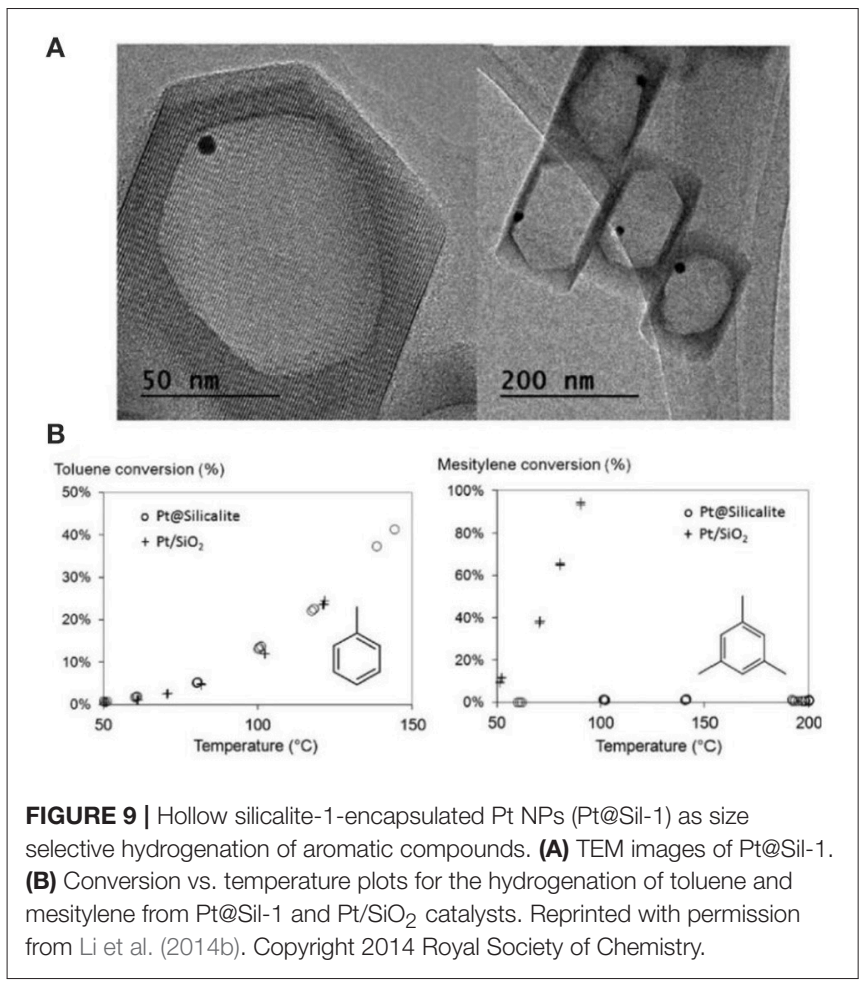

Pt@Sil-1 on the hydrogenation of bulky mesitylene (Figure 9B). Although the catalyst in this case did not perform the activity toward bulky molecules (only size selectivity), it reminds us that, if some mesopores are created on the zeolite shell (hollow mesoporous zeolites), corresponded catalytic performance will be greatly improved in both shape selectivity and bulky molecular catalysis. Owing to the presence of hierarchically macro-meso-micropores in one zeolite support, the composite catalysts after the encapsulation of metal NPs will be most efficient for various organic reactions.

As for the most cases mentioned above, the mesopores in the final catalysts are not particularly ordered, which may lead to the weak mass transfer efficiency compared to the ordered ones. How to construct a set of ordered mesopores inside the zeolites supports for the encapsulation of metal NPs is always a big challenging subject. The catalytic performances (e.g., conversion, shape selectivity, stability) in these expected catalysts should be greatly improved. The catalysts are theoretically employed in many fields of organic or small inorganic molecule reactions.

\section{SUMMARY AND PERSPECTIVES}

Mesoporous zeolite is a type of ideal inorganic supports for the encapsulation of metal NPs to produce composite catalysts

\section{REFERENCES}

Aijaz, A., Karkamkar, A., Choi, Y. J., Tsumori, N., Rönnebro, E., Autrey, T., et al. (2012). Immobilizing highly catalytically active Pt nanoparticles inside the for various organic reactions. In this review, the advantages of mesoporous zeolites as the supports are presented in detail with the comparison to other nanomaterials like metal or nonmetallic oxides, carbon, polymers, and porous frameworks. The main strategies for the construction of mesoporous zeolites and the encapsulation methods for metal NPs have been summarized as these two aspects are extremely important to combine mesoporous zeolites and metal NPs into composite catalysts. Several representative examples exhibited well-catalytic performances in reactant conversions, shape selectivities, and stabilities in many organic catalytic reactions. There are still a lot of challenges in the preparation of mesoporous zeoliteencapsulated metal NPs, such as the degree of mesoporous order, the dispersity and size distribution of encapsulated metal NPs, and the large-scale synthesis, and so on. Additionally, the structure-performance relationship between catalytic reactions and catalyst structures (different mesopores, micropores, and metals) should be carefully revealed in the future.

As for the construction of ordered mesoporous zeoliteencapsulated metal NP catalysts, some purposed strategies are presented. The appropriate process should be the onepot synthesis via the mixing of zeolite gel and optimized metallic precursors (Wu et al., 2014) under the presence of some special structural-directing surfactants ( $\mathrm{Na}$ et al., 2011) or ordered hard templates (Chen et al., 2011). The most metal precursors can be retained after the removal of templates and reduced in situ into NPs inside the micropores. In this way, the ordered mesopores can run throughout zeolite crystals and meanwhile metal NPs are tightly immobilized inside microporous frameworks, resulting in the higher mass transfer efficiency and enhanced catalytic activity, especially for the bulky molecular catalysis. We hope this review can provide useful insights on the synthesis of zeolites supported metal NP composite catalysts and the understanding of the relationship between the catalytic performance and nanostructure of composite catalysts.

\section{AUTHOR CONTRIBUTIONS}

All authors listed have made a substantial, direct and intellectual contribution to the work, and approved it for publication.

\section{ACKNOWLEDGMENTS}

This work is supported by National Natural Science Foundation of China (No. 21501095) and Jiangsu Specially Appointed Professor Plan. The authors also thank the supports from Priority Academic Program Development of Jiangsu Higher Education Institutions, National and Local Joint Engineering Research Center of Biomedical Functional Materials.

pores of metal-organic framework: a double solvents approach. J. Am. Chem. Soc. 134, 13926-13929. doi: 10.1021/ja3043905

Alessandro, T. (2002). Catalysis by Ceria and Related Materials. Singapore: World Scientific. 
Arico, A. S., Bruce, P., Scrosati, B., Tarascon, J.-M., and Van Schalkwijk, W. (2011). Nanostructured Materials for Advanced Energy Conversion and Storage Devices. Singapore: Nature Publishing Group, World Scientific.

Astruc, D. (2008). Nanoparticles and Catalysis. Hoboken, NJ: John Wiley \& Sons.

Astruc, D., Lu, F., and Aranzaes, J. R. (2005). Nanoparticles as recyclable catalysts: the frontier between homogeneous and heterogeneous catalysis. Angew. Chem. Int. Ed. 44, 7852-7872. doi: 10.1002/anie.200500766

Campelo, J. M., Luna, D., Luque, R., Marinas, J. M., and Romero, A. A. (2009). Sustainable preparation of supported metal nanoparticles and their applications in catalysis. ChemSusChem 2, 18-45. doi: 10.1002/cssc.200800227

Cao, A., Lu, R., and Veser, G. (2010). Stabilizing metal nanoparticles for heterogeneous catalysis. Phys. Chem. Chem. Phys. 12, 13499-13510. doi: $10.1039 / \mathrm{c} 0 \mathrm{cp} 00729 \mathrm{c}$

Capek, I. (2004). Preparation of metal nanoparticles in water-inoil (w/o) microemulsions. Adv. Colloid Interface Sci. 110, 49-74. doi: 10.1016/j.cis.2004.02.003

Challa, S. R., Delariva, A. T., Hansen, T. W., Helveg, S., Sehested, J., Hansen, P. L., et al. (2011). Relating rates of catalyst sintering to the disappearance of individual nanoparticles during Ostwald ripening. J. Am. Chem. Soc. 133, 20672-20675. doi: 10.1021/ja208324n

Chen, H., Wydra, J., Zhang, X., Lee, P. S., Wang, Z., Fan, W., et al. (2011). Hydrothermal synthesis of zeolites with three-dimensionally ordered mesoporous-imprinted structure. J. Am. Chem. Soc. 133, 12390-12393. doi: $10.1021 / \mathrm{ja} 2046815$

Chen, N., Degnan, T. F., and Smith, C. M. (1994). Molecular Transport and Reaction in Zeolites. New York, NY: John Wiley \& Sons.

Chen, Z., Chen, C., Zhang, J., Zheng, G., Wang, Y., Dong, L., et al. (2018). Zeolite Y microspheres with perpendicular mesochannels and metal@Y heterostructures for catalytic and SERS applications. J. Mater. Chem. A 6, 6273-6281. doi: 10.1039/c7ta10444h

Cheng, K., Zhang, L., Kang, J., Peng, X., Zhang, Q., and Wang, Y. (2015). Selective transformation of syngas into gasoline-range hydrocarbons over mesoporous H-ZSM-5-supported cobalt nanoparticles. Chem. Eur. J. 21, 1928-1937. doi: 10 $.1002 /$ chem.201405277

Choi, M., Na, K., Kim, J., Sakamoto, Y., Terasaki, O., and Ryoo, R. (2009). Stable single-unit-cell nanosheets of zeolite MFI as active and long-lived catalysts. Nature 461, 246-249. doi: 10.1038/nature08288

Choi, M., Wu, Z., and Iglesia, E. (2010). Mercaptosilane-assisted synthesis of metal clusters within zeolites and catalytic consequences of encapsulation. J. Am. Chem. Soc. 132, 9129-9137. doi: 10.1021/ja102778e

Ciesla, U., and Schüth, F. (1999). Ordered mesoporous materials. Microporous Mesoporous Mater. 27, 131-149. doi: 10.1016/S1387-1811(98)00249-2

Corbierre, M. K., Cameron, N. S., Sutton, M., Mochrie, S. G., Lurio, L. B., Rühm, A., et al. (2001). Polymer-stabilized gold nanoparticles and their incorporation into polymer matrices. J. Am. Chem. Soc. 123, 10411-10412. doi: 10.1021/ja0166287

Corma, A. (1997). From microporous to mesoporous molecular sieve materials and their use in catalysis. Chem. Rev. 97, 2373-2420. doi: 10.1021/cr960406n

Corma, A., Fornes, V., Pergher, S. B., Maesen, T. L. M., and Buglass, J. G. (1998). Delaminated zeolite precursors as selective acidic catalysts. Nature 396, 353-356. doi: 10.1038/24592

Crooks, R. M., Zhao, M., Sun, L., Chechik, V., and Yeung, L. K. (2001). Dendrimerencapsulated metal nanoparticles: synthesis, characterization, and applications to catalysis. Acc. Chem. Res. 34, 181-190. doi: 10.1021/ar000110a

Cuenya, B. R. (2010). Synthesis and catalytic properties of metal nanoparticles: size, shape, support, composition, and oxidation state effects. Thin Solid Films 518, 3127-3150. doi: 10.1016/j.tsf.2010.01.018

Cui, T. L., Ke, W. Y., Zhang, W. B., Wang, H. H., Li, X. H., and Chen, J. S. (2016). Encapsulating palladium nanoparticles inside mesoporous MFI zeolite nanocrystals for shape-selective catalysis. Angew. Chem. Int. Ed. 55, 9178-9182. doi: 10.1002/anie. 201602429

Cundy, C. S., and Cox, P. A. (2005). The hydrothermal synthesis of zeolites: Precursors, intermediates and reaction mechanism. Microporous Mesoporous Mater. 82, 1-78. doi: 10.1016/j.micromeso.2005.02.016

Dai, C., Zhang, A., Liu, M., Gu, L., Guo, X., and Song, C. (2016). Hollow alveoluslike nanovesicle assembly with metal-encapsulated hollow zeolite nanocrystals. ACS Nano 10, 7401-7408. doi: 10.1021/acsnano.6b00888

Davis, M. E. (2002a). Ordered porous materials for emerging applications. Nature 417, 813-821. doi: 10.1038/nature00785
Dhakshinamoorthy, A., and Garcia, H. (2012). Catalysis by metal nanoparticles embedded on metal-organic frameworks. Chem. Soc. Rev. 41, 5262-5284. doi: 10.1039/C2CS35047E

Dong, A., Ren, N., Yang, W., Wang, Y., Zhang, Y., Wang, D., et al. (2003). Preparation of hollow zeolite spheres and threedimensionally ordered macroporous zeolite monoliths with functionalized interiors. Adv. Funct. Mater. 13, 943-948. doi: 10.1002/adfm.2003 04405

Doyle, A. M., Shaikhutdinov, S. K., Jackson, S. D., and Freund, H. J. (2003). Hydrogenation on metal surfaces: why are nanoparticles more active than single crystals? Angew. Chem. Int. Ed. 42, 5240-5243. doi: $10.1002 /$ anie. 200352124

Dupont, J., Fonseca, G. S., Umpierre, A. P., Fichtner, P. F., and Teixeira, S. R. (2002). Transition-metal nanoparticles in imidazolium ionic liquids: recycable catalysts for biphasic hydrogenation reactions. J. Am. Chem. Soc. 124, 4228-4229. doi: 10.1021/ja025818u

Dupont, J., and Scholten, J. D. (2010). On the structural and surface properties of transition-metal nanoparticles in ionic liquids. Chem. Soc. Rev. 39, 1780-1804. doi: 10.1039/B822551F

Dyker, G. (1999). Transition metal catalyzed coupling reactions under $\mathrm{C}-\mathrm{H}$ activation. Angew. Chem. Int. Ed. 38, 1698-1712.

Egeblad, K., Christensen, C. H., Kustova, M., and Christensen, C. H. (2008). Templating mesoporous zeolites. Chem. Mater. 20, 946-960. doi: $10.1021 / \mathrm{cm} 702224 \mathrm{p}$

Farrusseng, D., and Tuel, A. (2016). Perspectives on zeolite-encapsulated metal nanoparticles and their applications in catalysis. New J. Chem. 40, 3933-3949. doi: $10.1039 / \mathrm{c} 5 \mathrm{nj} 02608 \mathrm{c}$

Gallon, B. J., Kojima, R. W., Kaner, R. B., and Diaconescu, P. L. (2007). Palladium nanoparticles supported on polyaniline nanofibers as a semiheterogeneous catalyst in water. Angew. Chem. Int. Ed. 46, 7251-7254. doi: 10.1002/anie.200701389

Gilroy, K. D., Ruditskiy, A., Peng, H. C., Qin, D., and Xia, Y. (2016). Bimetallic nanocrystals: syntheses, properties, and applications. Chem. Rev. 116, 10414-10472. doi: 10.1021/acs.chemrev.6b00211

Groen, J. C., Peffer, L. A., Moulijn, J. A., and Pérez-Ramírez, J. (2005). Mechanism of hierarchical porosity development in mfi zeolites by desilication: the role of aluminium as a pore-directing agent. Chem. Eur. J. 11, 4983-4994. doi: 10.1002/chem.200500045

Guo, P., Yan, N., Wang, L., and Zou, X. (2017). Database mining of zeolite structures. Cryst. Growth Des. 17, 6821-6835. doi: 10.1021/acs.cgd.7b0 1410.

Han, J., Cho, J., Kim, J.-C., and Ryoo, R. (2018). Confinement of supported metal catalysts at high loading in the mesopore network of hierarchical zeolites, with access via the microporous windows. ACS Catal. 8, 876-879. doi: 10.1021 /acscatal.7b04183

Hansen, T. W., DeLaRiva, A. T., Challa, S. R., and Datye, A. K. (2013). Sintering of catalytic nanoparticles: particle migration or Ostwald ripening? Acc. Chem. Res. 46, 1720-1730. doi: 10.1021/ar3002427

Hartwig, J. F. (1998). Transition metal catalyzed synthesis of arylamines and aryl ethers from aryl halides and triflates: scope and mechanism. Angew. Chem. Int. Ed. 37, 2046-2067

He, J., Kunitake, T., and Nakao, A. (2003). Facile in situ synthesis of noble metal nanoparticles in porous cellulose fibers. Chem. Mater. 15, 4401-4406. doi: $10.1021 / \mathrm{cm} 034720 \mathrm{r}$

Højholt, K. T., Laursen, A. B., Kegnæs, S., and Christensen, C. H. (2011). Sizeselective oxidation of aldehydes with zeolite encapsulated gold nanoparticles. Top. Catal. 54, 1026. doi: 10.1007/s11244-011-9722-x

Hosseiniamoli, H., Bryant, G., Kennedy, E. M., Mathisen, K., Nicholson, D., Sankar, G., et al. (2018). Understanding structure-function relationships in zeolite-supported Pd catalysts for oxidation of ventilation air methane. ACS Catal. 5852-5863. doi: 10.1021/acscatal.7b04462

Jacinto, M. J., Kiyohara, P. K., Masunaga, S. H., Jardim, R. F., and Rossi, L. M. (2008). Recoverable rhodium nanoparticles: synthesis, characterization and catalytic performance in hydrogenation reactions. Appl. Catal. A Gen. 338, 52-57. doi: 10.1016/j.apcata.2007.12.018

Jin, L., Liu, B., Duay, S. S., and He, J. (2017). Engineering surface ligands of noble metal nanocatalysts in tuning the product selectivity. Catalysts 7, 44 . doi: $10.3390 /$ catal 7020044 
Joo, S. H., Choi, S. J., Oh, I., Kwak, J., Liu, Z., Terasaki, O., et al. (2001). Ordered nanoporous arrays of carbon supporting high dispersions of platinum nanoparticles. Nature 412, 169-172. doi: 10.1038/35084046

Ju, C., Wang, Y., Huang, Y., and Fang, Y. (2015). Design of mesoporous KA zeolite supported sulfur-tolerant noble metal catalyst for naphthalene hydrogenation. Fuel 154, 80-87. doi: 10.1016/j.fuel.2015.03.035

Ju-Nam, Y., and Lead, J. R. (2008). Manufactured nanoparticles: an overview of their chemistry, interactions and potential environmental implications. Sci. Total Environ. 400, 396-414. doi: 10.1016/j.scitotenv.2008.06.042

Kamat, P. V. (2009). Graphene-based nanoarchitectures. Anchoring semiconductor and metal nanoparticles on a two-dimensional carbon support. J. Phys. Chem. Lett. 1, 520-527. doi: 10.1021/jz900265j

Kärger, J., and Ruthven, D. (1992). Diffusion in Zeolites. New York, NY: John Wiley.

Ke, W., Cui, T., Yu, Q., Wang, M., Lv, L., Wang, H., et al. (2017). Mesoporous HZSM-5 nanocrystals with programmable number of acid sites as "solid ligands" to activate Pd nanoparticles for C-C coupling reactions. Nano Res. 11, 874-881. doi: 10.1007/s12274-017-1698-9

Kim, J.-C., Lee, S., Cho, K., Na, K., Lee, C., and Ryoo, R. (2014). Mesoporous MFI zeolite nanosponge supporting cobalt nanoparticles as a Fischer-Tropsch catalyst with high yield of branched hydrocarbons in the gasoline range. ACS Catal. 4, 3919-3927. doi: 10.1021/cs500784v

Kitchens, C. L., and McLeod, M. C., Roberts, C. B. (2003). Solvent effects on the growth and steric stabilization of copper metallic nanoparticles in AOT reverse micelle systems. J. Phys. Chem. B 107, 11331-11338. doi: 10.1021/jp0354090

Kokotailo, G., Lawton, S., and Olson, D. (1978). Structure of synthetic zeolite ZSM-5. Nature 272, 437-438. doi: 10.1038/272437a0

Kosinov, N., Liu, C., Hensen, E. J. M., and Pidko, E. A. (2018). Engineering of transition metal catalysts confined in zeolites. Chem. Mater. 30, 3177-3198. doi: 10.1021 acs.chemmater.8b01311

Kralik, M., and Biffis, A. (2001). Catalysis by metal nanoparticles supported on functional organic polymers. J. Mol. Catal. A: Chem. 177, 113-138. doi: 10.1016/S1381-1169(01)00313-2

Kresge, C. T., Leonowicz, M. E., Roth, W. J., Vartuli, J. C., and Beck, J. S. (1992). Ordered mesoporous molecular sieves synthesized by a liquid-crystal template mechanism. Nature 359, 710-712. doi: 10.1038/359710a0

Laursen, A. B., Højholt, K. T., Lundegaard, L. F., Simonsen, S. B., Helveg, S., Schüth, F., et al. (2010). Substrate size-selective catalysis with zeoliteencapsulated gold nanoparticles. Angew. Chem. Int. Ed. 49, 3504-3507. doi: doi.org/10.1002/anie.200906977

Li, K., Valla, J., and Garcia-Martinez, J. (2014a). Realizing the commercial potential of hierarchical zeolites: new opportunities in catalytic cracking. ChemCatChem 6, 46-66. doi: 10.1002/cctc.201300345

Li, S., Boucheron, T., Tuel, A., Farrusseng, D., and Meunier, F. (2014b). Sizeselective hydrogenation at the subnanometer scale over platinum nanoparticles encapsulated in silicalite-1 single crystal hollow shells. Chem. Commun. 50, 1824-1826. doi: 10.1039/C3CC48648F

Li, S., Tuel, A., Laprune, D., Meunier, F., and Farrusseng, D. (2014c). Transition-metal nanoparticles in hollow zeolite single crystals as bifunctional and size-selective hydrogenation catalysts. Chem. Mater. 27, 276-282. doi: $10.1021 / \mathrm{cm} 503921 \mathrm{f}$

Li, Y., and Yu, J. (2014). New Stories of zeolite structures: their descriptions, determinations, predictions, and evaluations. Chem. Rev. 114, 7268-7316. doi: $10.1021 / \mathrm{cr} 500010 \mathrm{r}$

Liu, B., Jiang, T., Zheng, H., Dissanayke, S., Song, W., Federico, A., et al. (2017a). Nanoengineering of aggregation-free and thermally-stable gold nanoparticles in mesoporous frameworks. Nanoscale 9, 6380-6390. doi: 10.1039/C7NR01988B

Liu, B., Jin, L., Zhong, W., Lopes, A., Suib, S. L., and He, J. (2018). Ultrafine and ligand-free precious metal $(\mathrm{Ru}, \mathrm{Ag}, \mathrm{Au}, \mathrm{Rh}$ and $\mathrm{Pd})$ nanoclusters supported on phosphorus-doped carbon. Chem. Eur. J. 24, 2565-2569. doi: 10.1002/chem.201705504

Liu, B., Kuo, C. H., Chen, J., Luo, Z., Thanneeru, S., Li, W., et al. (2015). Ligand-assisted co-assembly approach toward mesoporous hybrid catalysts of transition-metal oxides and noble metals: photochemical water splitting. Angew. Chem. Int. Ed. 54, 9061-9065. doi: 10.1002/anie.201502892

Liu, B., Wang, P., Lopes, A., Jin, L., Zhong, W., Pei, Y., et al. (2017b). Au-carbon electronic interaction mediated selective oxidation of styrene. ACS Catal. 7, 3483-3488. doi: 10.1021/acscatal.7b01048
Liu, B., Yao, H., Song, W., Jin, L., Mosa, I. M., Rusling, J. F., et al. (2016). Ligandfree noble metal nanocluster catalysts on carbon supports via "soft" nitriding. J. Am. Chem. Soc. 138, 4718-4721. doi: 10.1021/jacs.6b01702

Liu, F., Willhammar, T., Wang, L., Zhu, L., Sun, Q., Meng, X., et al. (2012). ZSM-5 zeolite single crystals withb-axis-aligned mesoporous channels as an efficient catalyst for conversion of bulky organic molecules. J. Am. Chem. Soc. 134, 4557-4560. doi: 10.1021/ja300078q

Liu, J., Qiao, S. Z., Budi, H. S., and Lu, G. Q. (2010). Monodisperse yolkshell nanoparticles with a hierarchical porous structure for delivery vehicles and nanoreactors. Angew. Chem. 122, 5101-5105. doi: 10.1002/anie.2010 01252

Liu, L., and Corma, A. (2018). Metal catalysts for heterogeneous catalysis: from single atoms to nanoclusters and nanoparticles. Chem. Rev. 118, 4981-5079. doi: 10.1021 /acs.chemrev.7b00776

Liu, L., Diaz, U., Arenal, R., Agostini, G., Concepcion, P., and Corma, A. $(2017 \mathrm{c})$. Generation of subnanometric platinum with high stability during transformation of a 2D zeolite into 3D. Nat. Mater. 16, 132-138. doi: $10.1038 / \mathrm{nmat} 4757$

Liz-Marzán, L. M., and Lado-Touriño, I. (1996). Reduction and stabilization of silver nanoparticles in ethanol by nonionic surfactants. Langmuir 12, 3585-3589. doi: 10.1021/la951501e

Lopez-Orozco, S., Inayat, A., Schwab, A., Selvam, T., and Schwieger, W. (2011). Zeolitic materials with hierarchical porous structures. Adv. Mater. 23, 2602-2615. doi: 10.1002/adma.201100462

Lu, G., Li, S., Guo, Z., Farha, O. K., Hauser, B. G., Qi, X., et al. (2012). Imparting functionality to a metal-organic framework material by controlled nanoparticle encapsulation. Nat. Chem. 4, 310. doi: 10.1038/nchem.1272

Mandal, S., Roy, D., Chaudhari, R. V., and Sastry, M. (2004). Pt and Pd nanoparticles immobilized on amine-functionalized zeolite: excellent catalysts for hydrogenation and heck reactions. Chem. Mater. 16, 3714-3724. doi: $10.1021 / \mathrm{cm} 0352504$

Mendes, P. S. F., Taleb, A.-L., Gay, A.-S., Daudin, A., Bouchy, C., Silva, J. M., et al. (2017). Nanoscale insights into Pt-impregnated mixtures of zeolites. J. Mater Chem. A 5, 16822-16833. doi: 10.1039/c7ta02534c

Mielby, J., Abildstrøm, J. O., Wang, F., Kasama, T., Weidenthaler, C., and Kegnæs, S. (2014). Oxidation of bioethanol using zeolite-encapsulated gold nanoparticles. Angew. Chem. 126, 12721-12724. doi: 10.1002/ange.20140 6354

Möller, K., and Bein, T. (2013). Mesoporosity - a new dimension for zeolites. Chem. Soc. Rev. 42, 3689-3707. doi: 10.1039/c3cs35 $488 \mathrm{a}$

Moller, K., Yilmaz, B., Muller, U., and Bein, T. (2012). Nanofusion: mesoporous zeolites made easy. Chem. Eur. J. 18, 7671-7674. doi: 10.1002/chem.2012 00544

Moreno, I., Dummer, N. F., Edwards, J. K., Alhumaimess, M., Sanka, M., Sanz, R., et al. (2013). Selective oxidation of benzyl alcohol using in situ generated H 2 O 2 over hierarchical Au-Pd titanium silicalite catalysts. Catal. Sci. Technol. 3 , 2425-2434. doi: 10.1039/C3CY00493G

Moreno-Manas, M., and Pleixats, R. (2003). Formation of carbon-carbon bonds under catalysis by transition-metal nanoparticles. Acc. Chem. Res. 36, 638-643. doi: $10.1021 /$ ar020267y

Na, K., Choi, M., and Ryoo, R. (2013). Recent advances in the synthesis of hierarchically nanoporous zeolites. Microporous Mesoporous Mater. 166, 3-19. doi: 10.1016/j.micromeso.2012.03.054

Na, K., Jo, C., Kim, J., Cho, K., Jung, J., Seo, Y., et al. (2011). Directing zeolite structures into hierarchically nanoporous architectures. Science 333, 328-332. doi: $10.1126 /$ science. 1204452

Na, Y., Park, S., Han, S. B., Han, H., Ko, S., and Chang, S. (2004). Ruthenium-catalyzed heck-type olefination and Suzuki coupling reactions: studies on the nature of catalytic species. J. Am. Chem. Soc. 126, 250-258. doi: $10.1021 / \mathrm{ja} 038742 \mathrm{q}$

Narayanan, R., and El-Sayed, M. A. (2005). Catalysis with transition metal nanoparticles in colloidal solution: nanoparticle shape dependence and stability. J. Phys. Chem. B 109, 12663-12676. doi: 10.1021/jp051066p

Otto, T., Ramallo-López, J. M., Giovanetti, L. J., Requejo, F. G., Zones, S. I., and Iglesia, E. (2016). Synthesis of stable monodisperse AuPd, AuPt, and PdPt bimetallic clusters encapsulated within LTA-zeolites. J. Catal. 342, 125-137. doi: $10.1016 /$ j.jcat.2016.07.017 
Pagis, C., Morgado Prates, A. R., Farrusseng, D., Bats, N., and Tuel, A. (2016). Hollow zeolite structures: an overview of synthesis methods. Chem. Mater. 28, 5205-5223. doi: 10.1021/acs.chemmater.6b02172

Pan, C., Pelzer, K., Philippot, K., Chaudret, B., Dassenoy, F., Lecante, P., et al. (2001). Ligand-stabilized ruthenium nanoparticles: synthesis, organization, and dynamics. J. Am. Chem. Soc. 123, 7584-7593. doi: 10.1021/ja003961m

Parlett, C. M. A., Wilson, K., and Lee, A. F. (2013). Hierarchical porous materials: catalytic applications. Chem. Soc. Rev. 42, 3876-3893. doi: 10.1039/c2cs35378d

Perego, C., and Millini, R. (2013). Porous materials in catalysis: challenges for mesoporous materials. Chem. Soc. Rev. 42, 3956-3976. doi: 10.1039/c2cs35244c

Perez-Ramirez, J., Christensen, C. H., Egeblad, K., Christensen, C. H., and Groen, J. C. (2008). Hierarchical zeolites: enhanced utilisation of microporous crystals in catalysis by advances in materials design. Chem. Soc. Rev. 37, 2530-2542. doi: $10.1039 / \mathrm{b} 809030 \mathrm{k}$

Prieto, G., Tuysuz, H., Duyckaerts, N., Knossalla, J., Wang, G. H., and Schuth, F. (2016). Hollow nano- and microstructures as catalysts. Chem. Rev. 116, 14056-14119. doi: 10.1021/acs.chemrev.6b00374

Primo, A., and Garcia, H. (2014). Zeolites as catalysts in oil refining. Chem. Soc. Rev. 43, 7548-7561. doi: 10.1039/C3CS60394F

Ren, L., Guo, Q., Kumar, P., Orazov, M., Xu, D., Alhassan, S. M., et al. (2015). Selfpillared, single-unit-cell Sn-MFI zeolite nanosheets and their use for glucose and lactose isomerization. Angew. Chem. Int. Ed. Engl. 54, 10848-10851. doi: 10.1002/anie.201505334

Ren, N., Yang, Y., Shen, J., Zhang, Y., Xu, H., Gao, Z., et al. (2007). Novel, efficient hollow zeolitically microcapsulized noble metal catalysts. J. Catal. 251, 182-188. doi: 10.1016/j.jcat.2007.07.009

Rioux, R. M., Song, H., Hoefelmeyer, J. D., Yang, P., and Somorjai, G. A. (2005). High-surface-area catalyst design: synthesis, characterization, and reaction studies of platinum nanoparticles in mesoporous SBA-15 silica. J. Phys. Chem. B 109, 2192-2202. doi: 10.1021/jp048867x

Rowsell, J. L., and Yaghi, O. M. (2004). Metal-organic frameworks: a new class of porous materials. Microporous Mesoporous Mater. 73, 3-14. doi: 10.1016/j.micromeso.2004.03.034

Rubio-Marques, P., Rivero-Crespo, M. A., Leyva-Perez, A., and Corma, A. (2015). Well-defined noble metal single sites in zeolites as an alternative to catalysis by insoluble metal salts. J. Am. Chem. Soc. 137, 11832-11837. doi: $10.1021 /$ jacs.5b07304

Satterfield, C. N. (1970). Mass Transfer in Heterogeneous Catalysis. Cambridge: The MIT Press.

Schauermann, S., Nilius, N., Shaikhutdinov, S., and Freund, H-J. (2012). Nanoparticles for heterogeneous catalysis: new mechanistic insights. Acc. Chem. Res. 46, 1673-1681. doi: 10.1021/ar300225s

Schmid, G., Maihack, V., Lantermann, F., and Peschel, S. (1996). Ligand-stabilized metal clusters and colloids: properties and applications. J. Chem. Soc., Dalton Trans. 589-595. doi: 10.1039/DT9960000589

Schwieger, W., Machoke, A. G., Weissenberger, T., Inayat, A., Selvam, T., Klumpp, M., et al. (2016). Hierarchy concepts: classification and preparation strategies for zeolite containing materials with hierarchical porosity. Chem. Soc. Rev. 45, 3353-3376. doi: 10.1039/C5CS00599J

Serrano, D. P., Escola, J. M., and Pizarro, P. (2013). Synthesis strategies in the search for hierarchical zeolites. Chem. Soc. Rev. 42, 4004-4035. doi: $10.1039 / \mathrm{c} 2 \operatorname{cs} 35330 \mathrm{j}$

Shi, J., Wang, Y., Yang, W., Tang, Y., and Xie, Z. (2015). Recent advances of pore system construction in zeolite-catalyzed chemical industry processes. Chem. Soc. Rev. 44, 8877-8903. doi: 10.1039/c5cs00626k

Slater, A. G., and Cooper, A. I. (2015). Function-led design of new porous materials. Science 348:aaa8075. doi: 10.1126/science.aaa8075

Sun, Q., Wang, N., Bing, Q., Si, R., Liu, J., Bai, R., et al. (2017). Subnanometric hybrid $\mathrm{Pd}-\mathrm{M}(\mathrm{OH}) 2, \mathrm{M}=\mathrm{Ni}$, Co, clusters in zeolites as highly efficient nanocatalysts for hydrogen generation. Chem 3, 477-493. doi: 10.1016/j.chempr.2017.07.001

Sun, X., and Li, Y. (2004). Colloidal carbon spheres and their core/shell structures with noble-metal nanoparticles. Angew. Chem. Int. Ed. 43, 597-601. doi: 10.1002/ange.200352386

Tang, Y., Li, Y., Fung, V., Jiang, D. E., Huang, W., Zhang, S., et al. (2018). Single rhodium atoms anchored in micropores for efficient transformation of methane under mild conditions. Nat. Commun. 9, 1231. doi: 10.1038/s41467-018-03235-7
Tao, Y., Kanoh, H., Abrams, L., and Kaneko, K. (2006). Mesopore-modified zeolites: preparation, characterization, and applications. Chem. Rev. 106, 896-910. doi: 10.1021/cr040204o

Wan, Y., and Zhao, D. (2007). On the controllable soft-templating approach to mesoporous silicates. Chem. Rev. 107, 2821-2860. doi: 10.1021/cr068020s

Wang, G., Xu, S., Wang, L., Liu, Z., Dong, X., Wang, L., et al. (2018a). Fish-in-hole: rationally positioning palladium into traps of zeolite crystals for sinter-resistant catalysts. Chem. Commun. 54, 3274-3277. doi: 10.1039/c8cc00513c

Wang, L., Xu, S., He, S., and Xiao, F-S. (2018b). Rational construction of metal nanoparticles fixed in zeolite crystals as highly efficient heterogeneous catalysts. Nano Today 20, 74-83. doi: 10.1016/j.nantod.2018.04.004

Wang, L., Zhang, J., Yi, X., Zheng, A., Deng, F., Chen, C., et al. (2015). Mesoporous ZSM-5 zeolite-supported $\mathrm{Ru}$ nanoparticles as highly efficient catalysts for upgrading phenolic biomolecules. ACS Catal. 5, 2727-2734. doi: 10.1021/acscatal.5b00083

Wang, N., Sun, Q., Bai, R., Li, X., Guo, G., and Yu, J. (2016). In situ confinement of ultrasmall Pd clusters within nanosized silicalite-1 zeolite for highly efficient catalysis of hydrogen generation. J. Am. Chem. Soc. 138, 7484-7487. doi: $10.1021 /$ jacs.6b03518

Weitkamp, J. (2000). Zeolites and catalysis. Solid State Ionics 131, 175-188. doi: 10.1016/S0167-2738(00)00632-9

White, R. J., Luque, R., Budarin, V. L., Clark, J. H., and Macquarrie, D. J. (2009). Supported metal nanoparticles on porous materials. Methods and applications. Chem. Soc. Rev. 38, 481-494. doi: 10.1039/B802654H

Wildgoose, G. G., Banks, C. E., and Compton, R. G. (2006). Metal nanoparticles and related materials supported on carbon nanotubes: methods and applications. Small 2, 182-193. doi: 10.1002/smll.200500324

Wu, Z., Goel, S., Choi, M., and Iglesia, E. (2014). Hydrothermal synthesis of LTA-encapsulated metal clusters and consequences for catalyst stability, reactivity, and selectivity. J. Catal. 311, 458-468. doi: 10.1016/j.jcat.2013. 12.021

Xing, C., Shen, W., Yang, G., Yang, R., Lu, P., Sun, J., et al. (2014). Completed encapsulation of cobalt particles in mesoporous H-ZSM-5 zeolite catalyst for direct synthesis of middle isoparaffin from syngas. Catal. Commun. 55, 53-56. doi: 10.1016/j.catcom.2014.06.018

Xu, D., Jing, Z., Cao, F., Sun, H., and Che, S. (2014a). Surfactants with aromaticgroup tail and single quaternary ammonium head for directing singlecrystalline mesostructured zeolite nanosheets. Chem. Mater. 26, 4612-4619. doi: $10.1021 / \mathrm{cm} 502027 \mathrm{j}$

Xu, D., Ma, Y., Jing, Z., Han, L., Singh, B., Feng, J., et al. (2014b). $\pi-$ $\pi$ interaction of aromatic groups in amphiphilic molecules directing for single-crystalline mesostructured zeolite nanosheets. Nat. Commun. 5, 5262. doi: 10.1038/ncomms5262

Xu, X., Li, Y., Gong, Y., Zhang, P., Li, H., and Wang, Y. (2012). Synthesis of palladium nanoparticles supported on mesoporous $\mathrm{N}$-doped carbon and their catalytic ability for biofuel upgrade. J. Am. Chem. Soc. 134, 16987-16990. doi: $10.1021 /$ ja308139s

Yang, C. M., Liu, P. H., Ho, Y. F., Chiu, C. Y., and Chao, K. J. (2003). Highly dispersed metal nanoparticles in functionalized SBA-15. Chem. Mater. 15, 275-280. doi: 10.1021/cm020822q

Yang, H., Ma, C., Zhang, X., Li, Y., Cheng, J., and Hao, Z. (2018). Understanding the active sites of $\mathrm{Ag} /$ zeolites and deactivation mechanism of ethylene catalytic oxidation at room temperature. ACS Catal. 8, 1248-1258. doi: 10.1021/acscatal.7b02410

Zaarour, M., Dong, B., Naydenova, I., Retoux, R., and Mintova, S. (2014). Progress in zeolite synthesis promotes advanced applications. Microporous Mesoporous Mater. 189, 11-21. doi: 10.1016/j.micromeso.2013.08.014

Zhang, J., Rao, C., Peng, H., Peng, C., Zhang, L., Xu, X., et al. (2018). Enhanced toluene combustion performance over Pt loaded hierarchical porous MOR zeolite. Chem. Eng. J. 334, 10-18. doi: 10.1016/j.cej.2017.10.017

Zhang, J., Wang, L., Shao, Y., Wang, Y., Gates, B. C., and Xiao, F. S. (2017). A Pd@Zeolite catalyst for nitroarene hydrogenation with high product selectivity by sterically controlled adsorption in the zeolite micropores. Angew. Chem. Int. Ed. Engl. 56, 9747-9751. doi: 10.1002/anie.201703938

Zhang, X., Liu, D., Xu, D., Asahina, S., Cychosz, K. A., Agrawal, K. V., et al. (2012). Synthesis of self-pillared zeolite nanosheets by repetitive branching. Science 336, 1684-1687. doi: 10.1126/science.122 1111 
Zhao, D., Feng, J., Huo, Q., Melosh, N., Fredrickson, G. H., Chmelka, B. F., et al. (1998). Triblock copolymer syntheses of mesoporous silica with periodic 50 to 300 angstrom pores. Science 279, 548-552. doi: 10.1126/science.279.5350. 548

Zhao, X., Bao, X. Y., Guo, W., and Lee, F. Y. (2006). Immobilizing catalysts on porous materials. Mater. Today 9, 32-39. doi: 10.1016/S1369-7021(06)71388-8

Zhu, J., Zhu, Y., Zhu, L., Rigutto, M., van der Made, A., Yang, C., et al. (2014). Highly mesoporous single-crystalline zeolite beta synthesized using a nonsurfactant cationic polymer as a dual-function template. J. Am. Chem. Soc. 136, 2503-2510. doi: 10.1021/ja411117y

Zhu, Q-L., and Xu, Q. (2016). Encapsulation of ultrafine metal nanoparticles to high-surface-area materials and their catalytic applications. Chem 1, 220-245. doi: 10.1016/j.chempr.2016.07.005
Conflict of Interest Statement: The authors declare that the research was conducted in the absence of any commercial or financial relationships that could be construed as a potential conflict of interest.

The handling editor declared a past supervisory role with one of the authors BL.

Copyright $(\odot) 2018 \mathrm{Xu}, \mathrm{Lv}$ and Liu. This is an open-access article distributed under the terms of the Creative Commons Attribution License (CC BY). The use, distribution or reproduction in other forums is permitted, provided the original author(s) and the copyright owner(s) are credited and that the original publication in this journal is cited, in accordance with accepted academic practice. No use, distribution or reproduction is permitted which does not comply with these terms. 